\title{
Oxidation of carbon compounds by silica-derived oxygen within impact-induced vapor plumes
}

\author{
Ko Ishibashi ${ }^{1}$, Sohsuke Ohno ${ }^{1}$, Seiji Sugita ${ }^{2}$, Toshihiko Kadono ${ }^{3}$, and Takafumi Matsui ${ }^{1}$ \\ ${ }^{1}$ Planetary Exploration Research Center, Chiba Institute of Technology, Japan \\ ${ }^{2}$ Department of Complexity Science and Engineering, Graduate School of Frontier Sciences, University of Tokyo, Japan \\ ${ }^{3}$ School of Medicine, University of Occupational and Environmental Health, Japan
}

(Received July 2, 2010; Revised September 4, 2012; Accepted December 18, 2012; Online published August 23, 2013)

\begin{abstract}
Impact-induced vapor plumes produce a variety of chemical species, which may play an important role in the evolution of planetary surface environments. In most previous theoretical studies on chemical reactions within impact-induced vapor plumes, only volatile components are considered. Chemical reactions between silicates and volatile components have been neglected. In particular, silica $\left(\mathrm{SiO}_{2}\right)$ is important because it is the dominant component of silicates. Reactions between silica and carbon under static and carbon-rich "metallurgic" conditions $\left(\mathrm{C} / \mathrm{SiO}_{2} \gg 1\right)$ are known to occur to produce $\mathrm{CO}$ and $\mathrm{SiC}$. Actual impact vapor plumes, however, cool dynamically and have carbon-poor "meteoritic" composition $\left(\mathrm{C} / \mathrm{SiO}_{2} \ll 1\right)$. Reactions under such conditions have not been investigated, and final products in such reaction systems are not known well. Although $\mathrm{CO}$ and $\mathrm{SiO}$ are thermodynamically stable at high temperatures under carbon-poor conditions, $\mathrm{C}$ and $\mathrm{SiO}_{2}$ are stable at low temperatures. Thus, $\mathrm{CO}$ may not be able to survive the rapidly cooling process of vapor plumes. In this study, we conduct laser pulse vaporization (LPV) experiments and thermodynamic calculations to examine whether interactions between carbon and silica occur in rapidly cooling vapor plumes with meteoritic chemical compositions. The experimental results indicate that even in rapidly cooling vapor plumes with meteoritic compounds are rather efficiently oxidized by silica-derived oxygen and that substantial amounts of both $\mathrm{CO}_{2}$ and $\mathrm{CO}$ are produced. The calculation results also suggest that those oxidation reactions seen in LPV experiments might occur in planetary-scale vapor plumes regardless of impact velocity as long as silicates vaporize.
\end{abstract}

Key words: Impact-induced vapor plume, laser pulse vaporization, chemical reactions.

\section{Introduction}

When a hypervelocity impact occurs on a planetary surface, an impact-induced vapor plume is generated. Many chemical species are produced within impact vapor plumes and are released into the atmosphere of planets. These species may have played an important role in planetary climates and abiotic synthesis of organic materials (e.g., Fegley et al., 1986; Mukhin et al., 1989; Kasting, 1990; Chyba and Sagan, 1992; Kress and McKay, 2004). Thus, it is important to understand the molecular composition of products within impact-induced vapor plumes. Because of the complexity of chemical reactions in vapor plumes, however, the composition of produced gases within vapor plumes is poorly known. Among the complex chemical reactions, chemical reactions between silicates and carbon compounds are expected to play a particularly important role, but they have not been investigated extensively.

There are few studies that estimate the molecular composition of gases produced within impact-induced vapor plumes from asteroidal compositions (i.e., meteoritic), which contain silicates much more than comets. Such estimation would be very difficult because the effect of sil-

Copyright (c) The Society of Geomagnetism and Earth, Planetary and Space Sciences (SGEPSS); The Seismological Society of Japan; The Volcanological Society of Japan; The Geodetic Society of Japan; The Japanese Society for Planetary Sciences; TERRAPUB.

doi:10.5047/eps.2012.12.010 icates is not understood well. Previous theoretical studies on gases produced within vapor plumes generated by a comet impact consider chemical reactions within only volatile elements of comets, such as $\mathrm{C}, \mathrm{H}, \mathrm{O}, \mathrm{N}$, and $\mathrm{S}$, in calculating the molecular composition of produced gas; silicate components are removed from the calculation (e.g., McKay et al., 1989; Kress and McKay, 2004; Ishimaru et al., 2005; Hashimoto et al., 2007). This simplification appears to be appropriate for as a first-order approximation, since silicates are refractory and are expected to condense at temperatures much higher than the quenching temperatures of volatile species. However, if oxygen derived from thermally decomposed silicates participates in the chemical reactions among carbon compounds in impact-induced vapor plumes, the composition and the oxidation state of produced gases may differ greatly from the molecular composition predicted by calculations that neglect the oxidation effect of silicates.

Laser pulse vaporization experiments on terrestrial rocks and chondrites by Mukhin et al. (1989) show that the gas products in vapor plumes are composed mainly of oxidized species, such as $\mathrm{CO}$ and $\mathrm{CO}_{2}$, with small amounts of reduced species, such as hydrocarbons, $\mathrm{HCN}$, and aldehydes. They proposed that this is because oxygen derived from thermal decomposition of silicates oxidized carbon. The proposed reaction between carbon and silicate-derived oxygen, however, has not been investigated extensively. They 
suggest that thermal decomposition of silicates in vapor plumes leads to high oxygen fugacity at high temperatures (Gerasimov, 1987; Gerasimov et al., 1987), and this oxygen would react with carbon to produce $\mathrm{CO}$ or $\mathrm{CO}_{2}$. Nevertheless, silicate-derived oxygen might recombine back to silicates and not to $\mathrm{CO}$ or $\mathrm{CO}_{2}$, as mentioned above. Since Mukhin et al. (1989) used complex natural samples (terrestrial rocks and chondrites), it is difficult to specify what reactions occur. Furthermore, since oxygen might be contained in the form of volatile components, such as water, carbonates and sulfates, the effect of oxidization by silicatederived oxygen cannot be separated from that by volatilederived oxygen. Such uncertainties in main oxidizing agent, reaction path, and possible effect of water and hydroxyls will prevent us from investigating the conditions for this oxidation process and its reaction rate, which are very important for applying to real-world impact events on planetary surfaces.

In particular, silica $\left(\mathrm{SiO}_{2}\right)$ is a very important species because it is the dominant component of silicates and would control the overall thermodynamic parameters of vaporization of silicates (e.g., Gerasimov et al., 1998). Actually, the reactions between silica and carbon have been studied for many years because of their industrial importance, such as the production of iron, silicon, and silicon carbide. Experiments have shown that $\mathrm{SiO}_{2}$ reacts with $\mathrm{C}$ to generate $\mathrm{SiC}$ and $\mathrm{CO}$ under such "metallurgic" conditions, $\mathrm{C} / \mathrm{SiO}_{2} \gg 1$ (e.g., Klinger et al., 1966; Biernacki and Wotzak, 1989a). This is consistent with thermodynamic equilibrium calculations, which indicate that $\mathrm{SiC}$ and $\mathrm{CO}$ are stable at high temperatures. The reactions under such conditions are known to proceed via solid-solid and solid-vapor reaction paths in a well-controlled and static reaction cells or furnaces (Biernacki and Wotzak, 1989b; Klinger et al., 1966). These studies show that carbon is oxidized by silica-derived oxygen. Thus, silica cannot be readily excluded from the consideration of the composition of gases produced within impactinduced vapor plumes. Reactions in actual impact vapor plumes, however, may be greatly different from those in static metallurgic conditions. First, such reactions would be influenced by rapid cooling due to adiabatic expansion of vapor plumes. Second, the composition of the reaction system is not "metallurgic" $\left(\mathrm{C} / \mathrm{SiO}_{2} \gg 1\right)$ but "meteoritic" $\left(\mathrm{C} / \mathrm{SiO}_{2} \ll 1\right)$ that is produced by silicate-rich impactors. Reactions in such dynamic rapidly cooling reaction systems with a meteoritic composition have not been intensively studied before, and final products in such reaction systems have not been known either. Thermodynamic equilibrium calculations indicate that gaseous $\mathrm{SiO}$ and $\mathrm{CO}$ are generated at high temperatures under such $\mathrm{C} / \mathrm{SiO}_{2} \gg 1$ conditions. For example, under 1 bar condition, $\mathrm{SiO}$ and $\mathrm{CO}$ can coexist stably at $>2000 \mathrm{~K}$. However, at $<2000 \mathrm{~K} \mathrm{SiO}_{2}$ and $\mathrm{C}$ are stable, and neither $\mathrm{SiO}$ nor $\mathrm{CO}$ can exist stably. This means that although $\mathrm{SiO}$ and $\mathrm{CO}$ may be formed at a high temperature, they would react to yield $\mathrm{SiO}_{2}$ and $\mathrm{C}$ if the thermal equilibrium is maintained during the cooling of vapor plumes down to $<2000 \mathrm{~K}$. It is not known whether $\mathrm{SiO}$ and $\mathrm{CO}$ can survive the adiabatic cooling of vapor plumes. In other words, it is not clear that $\mathrm{SiO}_{2}$ can be an efficient oxidizing agent in impact-induced vapor clouds.
Thus, in this study we investigate the reaction between silica and carbon compounds under meteoritic conditions $\left(\mathrm{C} / \mathrm{SiO}_{2} \ll 1\right)$. We conduct both laser pulse vaporization (LPV) experiments and thermodynamic calculations to examine whether oxygen derived from $\mathrm{SiO}_{2}$ reacts with carbon within large-scale vapor plumes. Instead of complicated reaction systems, we consider simple reaction systems that simulate impacts of carbonaceous chondritic projectiles to investigate the effect of carbon oxidation by silica-derived oxygen. In both experiments and thermodynamic calculations, we consider reaction systems consisting of silica $\left(\mathrm{SiO}_{2}\right)$ and polyethylene (PE). First, we conduct LPV experiments, which have been used to simulate impact vaporization (e.g., Mukhin et al., 1989; Kadono et al., 2002; Managadze et al., 2003; Sugita et al., 2003; Ohno et al., 2004) and measure whether $\mathrm{CO}$ and/or $\mathrm{CO}_{2}$ are produced in even carbon-poor reaction systems. We use artificial samples, mixtures of silica powder and polyethylene powder, for investigating the effect of silica-derived oxygen. Since polyethylene is composed only of $\mathrm{C}$ and $\mathrm{H}\left(\left[\mathrm{CH}_{2}\right]_{\mathrm{n}}\right)$, production of $\mathrm{CO}$ or $\mathrm{CO}_{2}$ will indicate that silica-derived oxygen reacts with carbon in polyethylene. We also examine the effect of target mixing ratio of silica on the yields of $\mathrm{CO}$ and $\mathrm{CO}_{2}$ systematically. This set of experiments will also confirm whether silica-derived oxygen reacts with carbon. Furthermore, LPV experiments in different laser beam diameters and different laser intensities are performed to examine the robustness of the experimental results. Second, we perform thermodynamic equilibrium calculations that simulate reactions within vapor plumes and compare the results of thermodynamic equilibrium calculations and the results of LPV experiments.

\section{Experiments}

We conducted laser pulse vaporization (LPV) experiments using polyethylene-silica $\left(\mathrm{PE}-\mathrm{SiO}_{2}\right)$ targets with different silica mixing ratios to investigate the effect of silicaderived oxygen on the yields of carbon compounds. Similar LPV experiments were repeated under different laser irradiation conditions to examine the robustness of the results.

\subsection{Experimental methods}

We used LPV for generating hot vapor plumes and measured the composition of produced gases with a quadrupole mass spectrometer (QMS; HIDEN HAL/3F RC 301 PIC). The experimental technique we used is basically the same as that by Ohno et al. (2004). Experimental system consists of a Nd:YAG laser, a vacuum chamber with a X-Y stage, and a QMS (Fig. 1). The laser wavelength is $1.064 \mu \mathrm{m}$, the laser pulse width is $\sim 13 \mathrm{~ns}$, and the maximum energy of the laser pulse is $\sim 410 \mathrm{~mJ} /$ pulse. The laser ablation depth is typically on the order of its wavelength $\sim 1 \mu \mathrm{m}$ per pulse. The interval between irradiations was fixed at $2 \mathrm{sec}$, which is much longer than the time scale of vapor plume expansion $(\sim 10-100 \mu \mathrm{sec})$. Prescribed laser beam diameters and laser intensities on the surface of a target can be obtained by changing pulse energy and the distance between a beamfocusing lens and the surface of the targets. Nominal laser intensity we used is $1 \times 10^{9} \mathrm{~W} / \mathrm{cm}^{2}$. In this study, precise control for the elemental composition in the vapor plume is very important. Thus, stoichiometric ablation, in which 


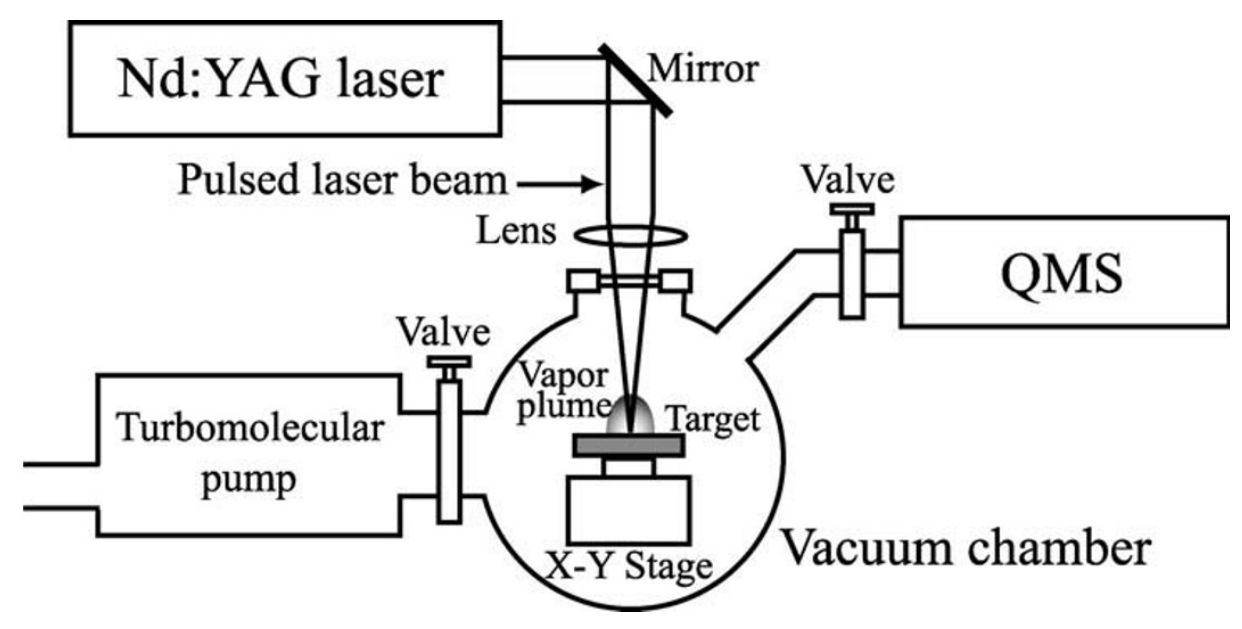

Fig. 1. Laser pulse vaporization experiment system.

Table 1. Mixing ratio and $\mathrm{C} / \mathrm{O}$ ratio of polyethylene-silica targets.

\begin{tabular}{ccc}
\hline silica/polyethylene (mass ratio) & silica/polyethylene (mole ratio) & O/C (mole ratio) \\
\hline 21.4 & 5 & 10 \\
4.73 & 2 & 4 \\
4.29 & 1 & 2 \\
2.14 & 0.5 & 1 \\
1.22 & 0.25 & 0.5 \\
\hline
\end{tabular}

the composition of the vaporized material is the same as the composition of the solid sample, is essential. Fractional vaporization is known to occur below $\sim 5 \times 10^{8} \mathrm{~W} / \mathrm{cm}^{2}$ for many materials. However, $1 \times 10^{9} \mathrm{~W} / \mathrm{cm}^{2}$ is sufficient for silicates and plastic materials to achieve stoichiometric ablation (e.g., Chan and Russo, 1991; Russo, 1995; Mao et al., 1996). Entropy gained by laser irradiation with such laser intensity is estimated to be equal to the entropy gained by hypervelocity impacts at velocities between several tens of km/s and a hundred km/s (Kadono et al., 2002; Sugita et al., 2003, 2012).

Note that the laser we used does not have a very flat beam profile. As long as the beam profile is constant, however, we can obtain data on the effect of laser intensity and beam size to final gas composition. Laser beam pattern, nevertheless, may actually change when the output energy and frequency of the laser unit are changed. Thus, instead of changing the output energy of the laser unit itself, we controlled the output laser energy by using different numbers of beam splitters for different runs. This way the output energy and frequency of the laser always stay the same, ensuring the laser beam pattern be the same. Consequently, the result of experiments can be compared safely among different laser intensities despite the inhomogeneous laser energy distribution within the beam.

We used mixtures of polyethylene and silica as targets. Polyethylene was used because it is a pure carbon compound. Although some commercially available plastics may contain bonding chemical agents, we used pure polyethylene samples without additional agents other than $\left[\mathrm{CH}_{2}\right]_{\mathrm{n}}$. Polyethylene consists only of carbon and hydrogen, and the elemental ratio of $\mathrm{C}$ to $\mathrm{H}$ is 0.5 . Since polyethylene contains no oxygen, production of oxygen-bearing gases, such as $\mathrm{CO}$ or $\mathrm{CO}_{2}$, indicates that reactions between silica-derived oxygen and carbon of polyethylene occur within vapor plumes. The average size of silica and polyethylene powder is $\sim 5$ $\mu \mathrm{m}$. We changed the mixing ratio of silica in targets systematically and examined the effect of target composition on the yields of $\mathrm{CO}$ and $\mathrm{CO}_{2}$ to investigate whether silicaderived oxygen reacts with carbon. The powder mixtures were compressed into solid tablets. The mixing ratio of polyethylene to silica and the elemental composition (the $\mathrm{O} / \mathrm{C}$ ratio) of $\mathrm{PE}-\mathrm{SiO}_{2}$ targets are listed in Table 1 . The $\mathrm{O} / \mathrm{C}$ ratio of the targets ranges from 0.5 to 10 . This range is slightly smaller than the $\mathrm{O} / \mathrm{C}$ ratio of typical carbonaceous chondrites $(\sim 11$ for $\mathrm{CI}$ chondrites and $\sim 15$ for CM chondrites; calculated using the mean elemental compositions of chondrites by Wasson and Kallemeyn (1988)).

Because polyethylene consists only of $\mathrm{C}$ and $\mathrm{H}$, either $\mathrm{CO}$ or $\mathrm{CO}_{2}$ cannot be produced from a pure polyethylene target. If there were other oxygen sources, such as water adsorption on the surface of targets, $\mathrm{CO}$ and $\mathrm{CO}_{2}$ would be produced. However, neither $\mathrm{CO}$ nor $\mathrm{CO}_{2}$ were detected from the LPV experiments using polyethylene-only targets. This indicates that there is no substantial amount of water adsorption on the surface of targets or that such a possible reaction between absorbed water and carbon is not efficient.

A target was placed on the $\mathrm{X}-\mathrm{Y}$ stage in the vacuum chamber before each set of experiments. The X-Y stage can be moved in $\mathrm{x}$ and $\mathrm{y}$ directions to avoid irradiating laser to the same spot on the target. Before each set of experiments, the vacuum chamber was evacuated with a turbo-molecular pump down to $\sim 1 \times 10^{-8}$ mbar and baked at $200^{\circ} \mathrm{C}$ for $\sim 10$ hours to remove the materials adsorbed on the inner walls of the chamber. After the vacuum chamber cooled and reached room temperature, we conducted 
(a)

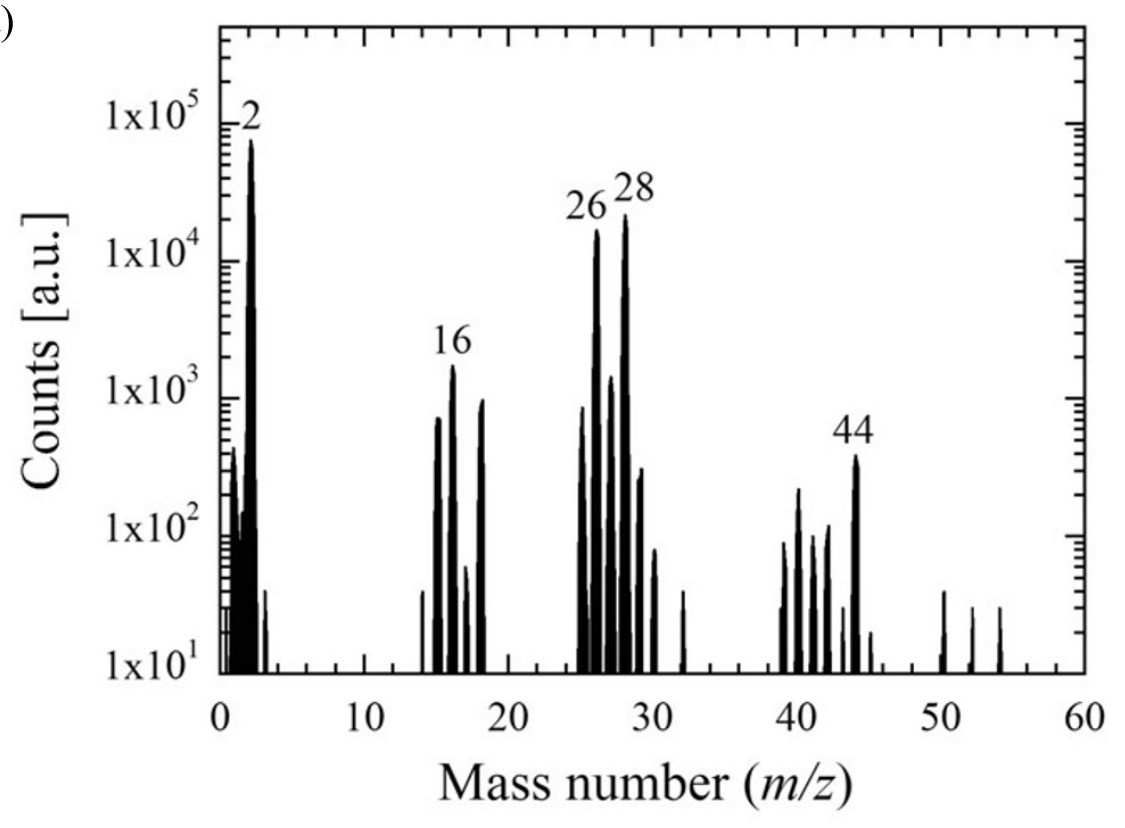

(b)

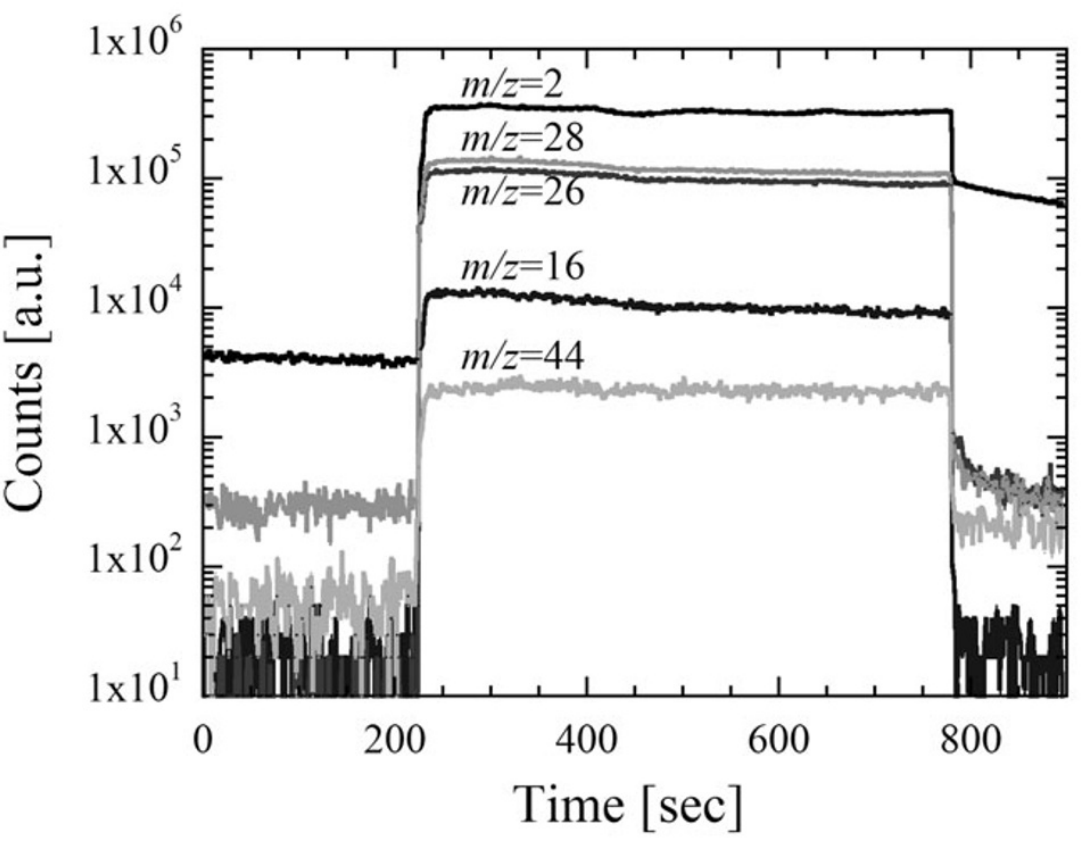

Fig. 2. Examples of (a) mass spectrum and (b) time-series data of main products $(\mathrm{PE}-\mathrm{SiO} 2 \operatorname{target}, \mathrm{O} / \mathrm{C}=2)$. A valve of QMS was opened at $\sim 230$ seconds and closed at $\sim 780$ seconds. The relative abundances of each chemical species are obtained by sensitivity calibration using standard gases and separating the chemical species on the same mass number (see text).

LPV experiments. The target was irradiated with pulsed laser beams repeatedly for a few minutes to $\sim 30$ minutes depending on the amount of vaporization, which changes with the laser-irradiation condition. Pressure in the vacuum chamber during a QMS measurement was kept at $\sim 1 \times 10^{-3}$ mbar filled with gases generated by laser irradiation. If the chamber pressure is lower than this level, pressure fluctuation due to each laser-induced degassing causes a significant noise in QMS measurements. When the pressure in the vacuum chamber reached $\sim 1 \times 10^{-3}$ mbar, the valve between the chamber and the QMS was opened to measure the produced gases. Figures 2(a) and (b) show the exam- ples of a mass spectrum and a time-series data of main mass numbers, respectively. Obtained time-series data were statistically processed to determine the relative abundance of chemical species. Chemical species observed on the same mass numbers, such as $\mathrm{CO}$ and $\mathrm{C}_{2} \mathrm{H}_{4}$ (mass number 28), are separated using fragmentation pattern and/or isotopic ion ratio. A sensitivity calibration of the QMS was conducted using standard gases.

\subsection{Experimental results}

In the main experiments, we first fixed the laser irradiation condition (i.e., $1 \mathrm{~mm}$ in beam diameter and $1 \times 10^{9}$ $\mathrm{W} / \mathrm{cm}^{2}$ in laser intensity) and investigated the effect of the 
(a)
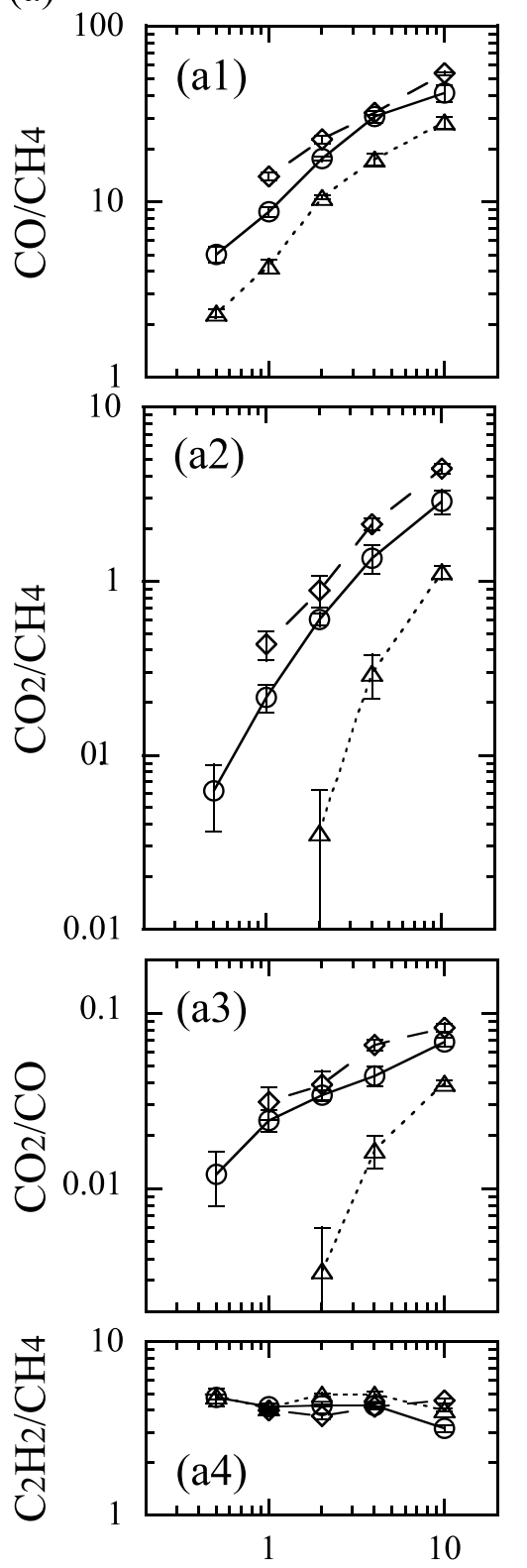

$\mathrm{O} / \mathrm{C}$ of target (b)
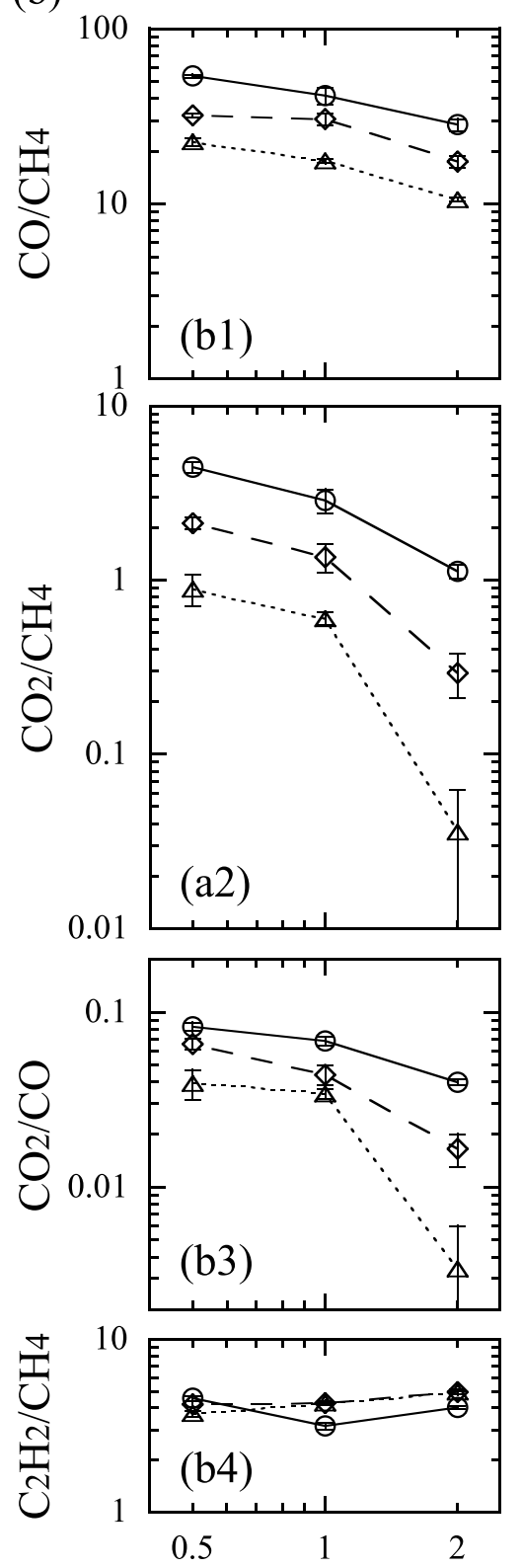

Beam diameter $[\mathrm{mm}]$

\begin{tabular}{|ll|}
\hline$\diamond$ & $0.5 \mathrm{~mm}$ \\
$\bigcirc$ & $1 \mathrm{~mm}$ \\
$\triangle$ & $2 \mathrm{~mm}$ \\
\hline
\end{tabular}

Fig. 3. Results of $\mathrm{PE}-\mathrm{SiO}_{2}$ target. (a) the $\mathrm{CO} / \mathrm{CH}_{4}, \mathrm{CO}_{2} / \mathrm{CH}_{4}, \mathrm{CO}_{2} / \mathrm{CO}$, and $\mathrm{C}_{2} \mathrm{H}_{2} / \mathrm{CH}_{4}$ ratio of the produced gas as functions of $\mathrm{O} / \mathrm{C}$ ratio of targets. Results of $0.5,1$ and $2 \mathrm{~mm}$ laser beam diameter (laser intensity is fixed at $1 \times 10^{9} \mathrm{~W} / \mathrm{cm}^{2}$ ) are shown. Solid line shows the result of nominal case; laser beam diameter $1 \mathrm{~mm}$ and laser intensity $1 \times 10^{9} \mathrm{~W} / \mathrm{cm}^{2}$. (b) The $\mathrm{CO} / \mathrm{CH}_{4}, \mathrm{CO}_{2} / \mathrm{CH}_{4}, \mathrm{CO}_{2} / \mathrm{CO}$, and $\mathrm{C}_{2} \mathrm{H}_{2} / \mathrm{CH}_{4}$ ratio of the produced gas as functions of laser beam diameter. Results of $\mathrm{O} / \mathrm{C}=10,4$ and 2 are shown.

$\mathrm{SiO}_{2}$ ratio of targets on the composition of produced gases. If silica-derived oxygen is used in the reaction with carbon compounds, the yields of the oxygen-bearing carbon species, $\mathrm{CO}$ and/or $\mathrm{CO}_{2}$, will increase as the silica ratio of targets increases.

The results indicate that more carbon oxides $\left(\mathrm{CO}+\mathrm{CO}_{2}\right)$ are generated than major hydrocarbons under these conditions; the $\left(\mathrm{CO}+\mathrm{CO}_{2}\right) /\left(\mathrm{CH}_{4}+\mathrm{C}_{2} \mathrm{H}_{2}\right)$ ratio ranges from 1 to 10 . The specific ratios of individual species are shown in Fig. 3 with the solid line. Figures 3(a1) to (a4) show the $\mathrm{CO} / \mathrm{CH}_{4}, \mathrm{CO}_{2} / \mathrm{CH}_{4}, \mathrm{CO}_{2} / \mathrm{CO}$, and $\mathrm{C}_{2} \mathrm{H}_{2} / \mathrm{CH}_{4}$ ratios as functions of the $\mathrm{O} / \mathrm{C}$ ratio of targets, respectively. Those are the main carbon-bearing species detected by the QMS. The average of several experimental runs under the same conditions are taken in order to increase the accuracy of the data. Errors are calculated from scatter of the data and shown as error bars in Fig. 3. These results clearly indicate that $\mathrm{CO}$ and $\mathrm{CO}_{2}$ were generated. This unambiguously indicates that silica-derived oxygen reacts with carbon of polyethylene. In addition, the $\mathrm{CO} / \mathrm{CH}_{4}, \mathrm{CO}_{2} / \mathrm{CH}_{4}$, and 
$\mathrm{CO}_{2} / \mathrm{CO}$ ratios of produced gas increase monotonically as the $\mathrm{O} / \mathrm{C}$ ratio of targets (i.e. silica ratio in targets) increases (Figs. 3(a) and (b)). In other words, the ratio of more oxidizing species to less oxidizing species in produced gas increases as the silica ratio in targets increases. This is consistent with a chemical reaction between silica-derived oxygen and carbon.

Note that the $\mathrm{C}_{2} \mathrm{H}_{2} / \mathrm{CH}_{4}$ does not depend on target silica ratio (solid line of Fig. 3(a4)). This strange behavior of hydrocarbons is also reported in the previous LPV experiments by Gerasimov (2002), which shows that the ratios of hydrocarbons are almost the same regardless of the experimental conditions. He suggested that Fischer-Tropsch type catalytic reactions, which produce hydrocarbons from $\mathrm{CO}$ and $\mathrm{H}_{2}$ on the surface of nano-scale condensed particles, may occur. The same type reactions may occur in our experiments as well. Another possible hydrocarbon source is the polyethylene melts generated by laser irradiation. Hydrocarbons may degassed from the melts. Although we cannot tell which process may be the case at this point, both possible case would suggest that most of the hydrocarbons detected in our experiments are not gas-phase reaction products within vapor plumes but produced by subsequent catalytic reactions or secondary degassing from melts around the ablation crater. This would further support that the main carbon-bearing species produced within high-temperature vapor plumes are most likely $\mathrm{CO}$ and $\mathrm{CO}_{2}$.

In order to examine the robustness of the above results, first we conducted similar experiments with different diameters of laser beam on the surface of targets $(0.5$ to 2 $\mathrm{mm}$ ) while the laser intensity was fixed at $1 \times 10^{9} \mathrm{~W} / \mathrm{cm}^{2}$. Second, laser intensity was changed from $1 \times 10^{9}$ to $2 \times 10^{9}$ $\mathrm{W} / \mathrm{cm}^{2}$ while the laser beam diameter was fixed at $1 \mathrm{~mm}$. Figures 3(a) compares the results of the experiments with laser beam diameter $0.5,1$, and $2 \mathrm{~mm}$. Significant amounts of both $\mathrm{CO}$ and $\mathrm{CO}_{2}$ are also produced with beam diameters different from the nominal value $(1 \mathrm{~mm})$. The dependence on the $\mathrm{O} / \mathrm{C}$ ratio of targets observed for both 0.5 and $2 \mathrm{~mm}$ cases are similar to the case of $1 \mathrm{~mm}$ laser beam diameter. The $\mathrm{CO} / \mathrm{CH}_{4}, \mathrm{CO}_{2} / \mathrm{CH}_{4}$, and $\mathrm{CO}_{2} / \mathrm{CO}$ ratios increase as the $\mathrm{O} / \mathrm{C}$ ratio of targets increases (Figs. 3(a1) to (a3)), and the $\mathrm{C}_{2} \mathrm{H}_{2} / \mathrm{CH}_{4}$ ratios are nearly constant for all the $\mathrm{O} / \mathrm{C}$ ratios of targets (Figs. 3(a4)). Figures 4(a) compares the results of the experiments with laser intensity of $1 \times 10^{9}$ and $2 \times 10^{9} \mathrm{~W} / \mathrm{cm}^{2}$. Significant amounts of both $\mathrm{CO}$ and $\mathrm{CO}_{2}$ are also produced with laser intensity different from the nominal value $\left(1 \times 10^{9} \mathrm{~W} / \mathrm{cm}^{2}\right)$. The dependence on the target $\mathrm{O} / \mathrm{C}$ ratio was also similar between $2 \times 10^{9} \mathrm{~W} / \mathrm{cm}^{2}$ and $1 \times 10^{9} \mathrm{~W} / \mathrm{cm}^{2}$ of laser intensity. The $\mathrm{CO} / \mathrm{CH}_{4}, \mathrm{CO}_{2} / \mathrm{CH}_{4}$, and $\mathrm{CO}_{2} / \mathrm{CO}$ ratios increase as the $\mathrm{O} / \mathrm{C}$ ratios of targets increase (Figs. 4(a1) to (a3)), and the $\mathrm{C}_{2} \mathrm{H}_{2} / \mathrm{CH}_{4}$ ratios are nearly constant for all the $\mathrm{O} / \mathrm{C}$ ratios of targets (Figs. 4(a4)). Note that the $\mathrm{C}_{2} \mathrm{H}_{2} / \mathrm{CH}_{4}$ ratio is almost the same under all the laser-irradiation conditions (Figs. 3(b4) and 4(b4)). This supports the idea proposed above that those hydrocarbons might not be produced by gas-phase reactions within hightemperature vapor plumes but produced by catalytic reactions on nano-scale particles generated with laser irradiation or generated from polyethylene melts on the floor and wall of the crater made by laser irradiation.
For all the laser beam diameters and laser intensities we examined, $\mathrm{CO}$ and $\mathrm{CO}_{2}$ are produced. Furthermore, those are always the dominant carbon-bearing species produced within the vapor plumes in this study. The dependence of the $\mathrm{CO} / \mathrm{CH}_{4}, \mathrm{CO}_{2} / \mathrm{CH}_{4}$, and $\mathrm{CO}_{2} / \mathrm{CO}$ ratios on the target composition (the $\mathrm{O} / \mathrm{C}$ ratio of target) is also the same as the nominal case of $1 \mathrm{~mm}$ laser beam diameter and $1 \times 10^{9}$ $\mathrm{W} / \mathrm{cm}^{2}$ of laser intensity (Figs. 3(a) and 4(a)). These results indicate that the reaction between silica-derived oxygen and carbon in polyethylene is not limited to only one specific experimental condition but is applicable to multiple experimental conditions; implying the possibility that the same reaction may occur under a rather wide range of conditions. This suggests that even in meteoritic carbon-poor reaction systems silica-derived oxygen oxidizes carbon compounds within vapor plumes to produce $\mathrm{CO}$ and $\mathrm{CO}_{2}$.

Here, it is noted that the $\mathrm{CO} / \mathrm{CH}_{4}, \mathrm{CO}_{2} / \mathrm{CH}_{4}$, and $\mathrm{CO}_{2} / \mathrm{CO}$ ratios decrease as laser beam diameter increases (Fig. 3(b1) to (b3)) and that the $\mathrm{CO} / \mathrm{CH}_{4}, \mathrm{CO}_{2} / \mathrm{CH}_{4}$, and $\mathrm{CO}_{2} / \mathrm{CO}$ ratios decrease as laser intensity increases (Fig. 4(b1) to (b3)). We will discuss these dependences in Section 3.2 comparing with the results of thermodynamic calculations.

\section{Thermodynamic Equilibrium Calculations}

Experimental results discussed in the previous section show that carbon compounds are oxidized by silica-derived oxygen within vapor plumes by the LPV experiments. In this section we discuss whether the results of LPV experiments can be accounted for by a simple thermodynamic model. Thermodynamic calculations are carried out (Section 3.1), and the results are compared with the results of LPV experiments (Section 3.2).

\subsection{Model}

We carried out thermodynamic equilibrium calculations using Gibbs free energy minimization method (e.g., Prigogine and Defay, 1954) to simulate LPV experiments described in the previous section and to estimate the composition of products.

In our calculations, the following assumptions were used. (1) Products are always in a chemical equilibrium. (2) Vapor plumes cool adiabatically. Thus, the temperature and pressure of the vapor plumes change along isentropic paths, whose entropies are determined by laser ablation. The composition of products is estimated along those pressuretemperature paths. (3) The composition of products is determined by a single quenching; all reactions quench at one quenching temperature. Quenching temperature is the temperature where chemical reaction rate and cooling rate of vapor plume become the same. Since the cooling rate of vapor plumes decreases as the scale of a vapor plume increases, quenching temperature decreases as the scale of a vapor plume increases. In general, quenching temperature of reactions within vapor plumes of LPV experiments (i.e., millimeter-scale vapor plumes) is estimated to be $\sim 3000$ $\mathrm{K}$ and that of vapor plumes produced by impactors several kilometers in diameter is $\sim 2000 \mathrm{~K}$ (e.g., Gerasimov et al., 1998). In our calculation, the composition of products is determined as a function of quenching temperature.

It is difficult to know exactly the entropy gained by laser 
(a)
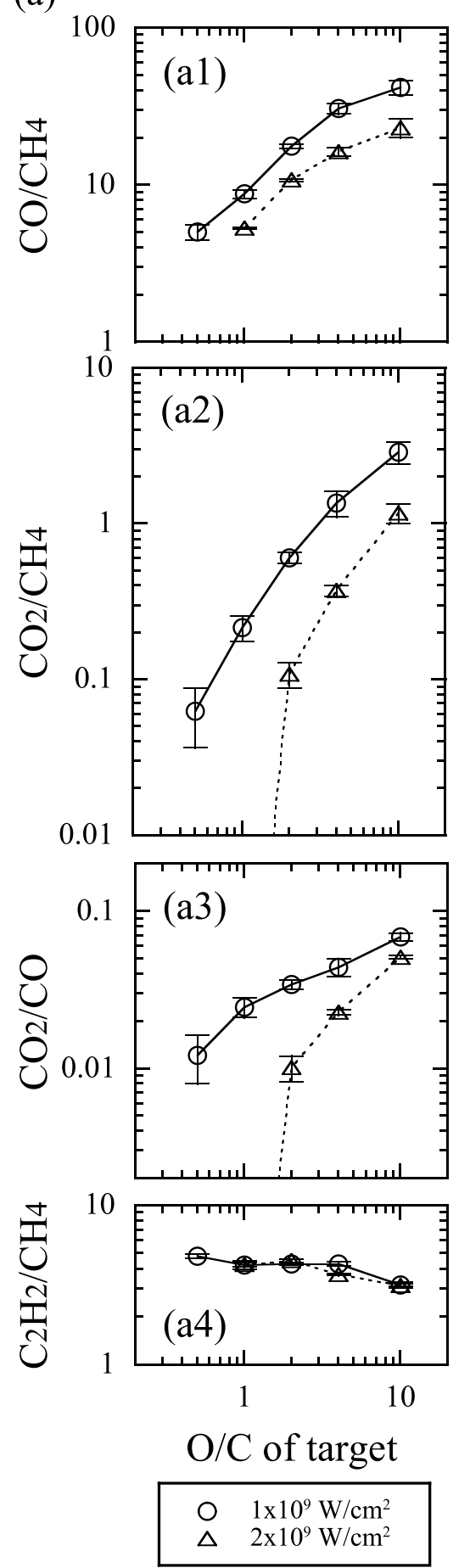

(b)
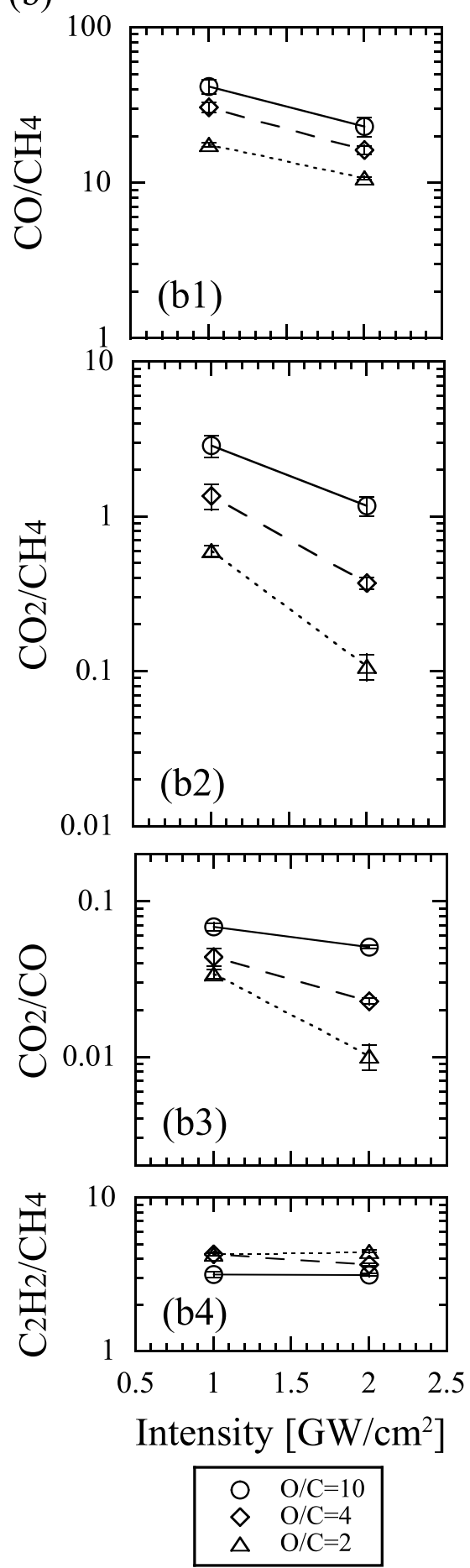

Fig. 4. Results of $\mathrm{PE}-\mathrm{SiO}_{2}$ target. (a) The $\mathrm{CO} / \mathrm{CH}_{4}, \mathrm{CO}_{2} / \mathrm{CH}_{4}, \mathrm{CO}_{2} / \mathrm{CO}$, and $\mathrm{C}_{2} \mathrm{H}_{2} / \mathrm{CH}_{4}$ ratio of the produced gas as functions of $\mathrm{O} / \mathrm{C}$ ratio of targets. Results of $1 \times 10^{9} \mathrm{~W} / \mathrm{cm}^{2}$ and $2 \times 10^{9} \mathrm{~W} / \mathrm{cm}^{2}$ laser intensity (laser beam diameter is fixed at $1 \mathrm{~mm}$ ) are shown. Solid line shows the result of nominal

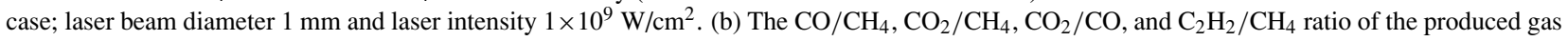
as functions of laser intensity. Results of $\mathrm{O} / \mathrm{C}=10,4$ and 2 are shown.

ablation on $\mathrm{PE}-\mathrm{SiO}_{2}$ targets. According to Sugita et al. (2003), gained entropy is $\sim 10 \mathrm{~kJ} / \mathrm{K} / \mathrm{kg}$ for laser intensity $1.0 \times 10^{9} \mathrm{~W} / \mathrm{cm}^{2}$ on a basalt target. Silica might absorb less energy than basalt because of its lower absorbance at the laser wavelength. Thus, we consider four adiabatic paths, $S=7,8,9$, and $10 \mathrm{~kJ} / \mathrm{K} / \mathrm{kg}$, along which the equilibrium composition is determined.

The elemental ratio of the reaction system is $\mathrm{C} / \mathrm{H} / \mathrm{O} / \mathrm{Si}$
$=1 / 2 / 10 / 5$, which corresponds to the $\mathrm{PE}-\mathrm{SiO}_{2}$ mixture of $\mathrm{SiO}_{2} / \mathrm{PE}=5$, the most carbon-poor target used in the LPV experiments. Species considered in the calculations are listed in Table 2. Thermodynamical data except for SiO species $\left(\mathrm{SiO}_{2}(\mathrm{l}), \mathrm{SiO}(\mathrm{s}), \mathrm{SiO}(\mathrm{g}), \mathrm{Si}(\mathrm{s})\right.$, and $\left.\mathrm{Si}(\mathrm{g})\right)$ are obtained from the JANAF tables (Chase et al., 1985). Thermodynamical data of $\mathrm{Si}-\mathrm{O}$ species are obtained from Hallstedt (1992). 
Table 2. Species considered in the thermodynamic equilibrium calculation and thermodynamical data used.

\begin{tabular}{cc}
\hline $\mathrm{SiO}_{2}(\mathrm{l}), \mathrm{SiO}(\mathrm{g}), \mathrm{SiO}(\mathrm{s}), \mathrm{Si}(\mathrm{s}), \mathrm{Si}(\mathrm{g})$ & Hallstedt (1992) \\
\hline $\mathrm{SiC}(\mathrm{s}), \mathrm{SiC}(\mathrm{g})$ & Chase et al. $(1985)$ \\
$\mathrm{CO}_{2}(\mathrm{~g}), \mathrm{CO}(\mathrm{g}), \mathrm{CH}_{4}(\mathrm{~g}), \mathrm{C}_{2} \mathrm{H}_{2}(\mathrm{~g})$, graphite $(\mathrm{s})$ & \\
$\mathrm{O}(\mathrm{g}), \mathrm{O}_{2}(\mathrm{~g}), \mathrm{H}(\mathrm{g}), \mathrm{H}_{2}(\mathrm{~g}), \mathrm{H}_{2} \mathrm{O}(\mathrm{g})$ & \\
g: gas, l: liquid, s: solid. &
\end{tabular}
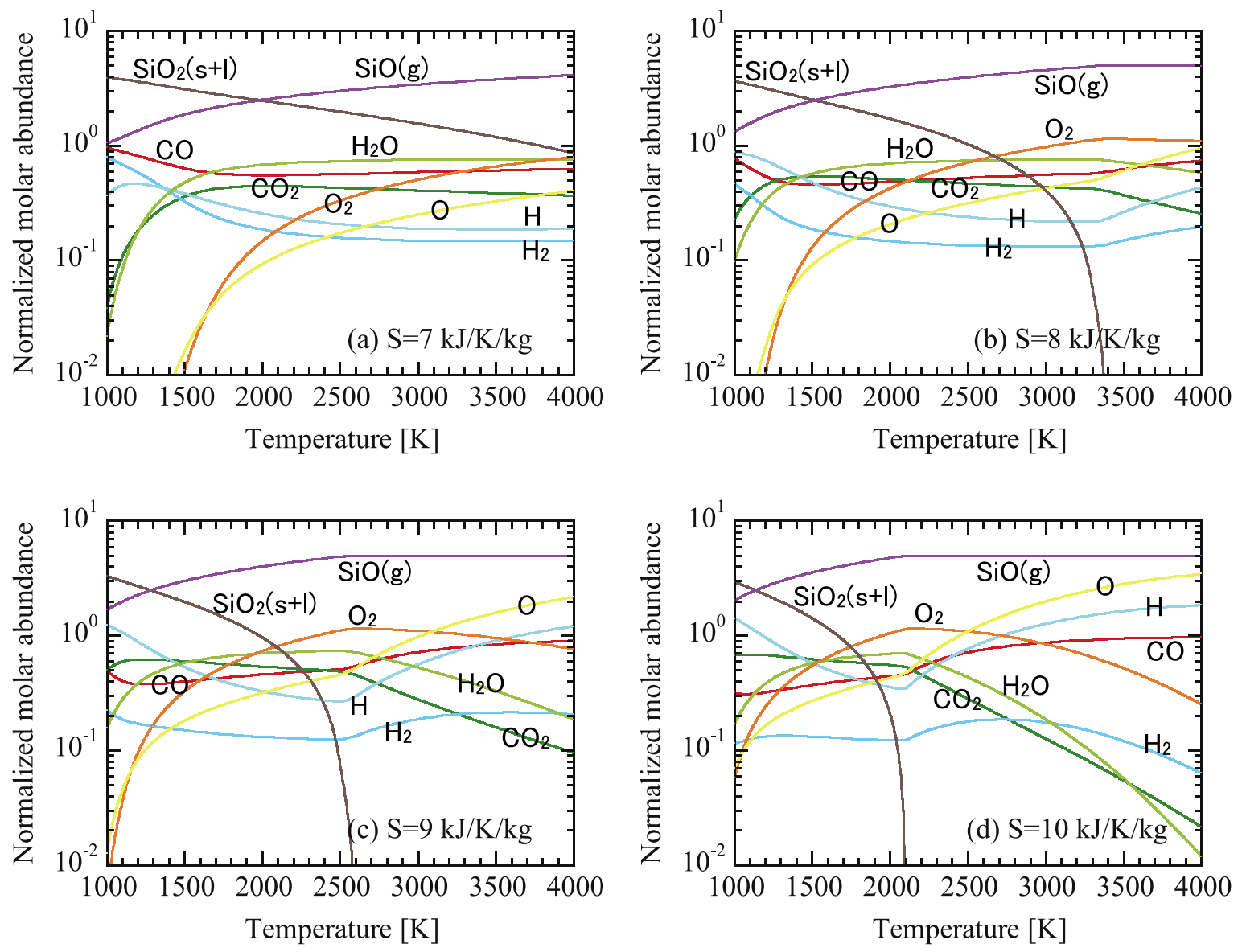

Fig. 5. Results of thermodynamic equilibrium calculation along isentropic pressure-temperature paths. The amount of species normalized by the total number of moles of $\mathrm{C}$ atoms in the reaction system is plotted as a function of temperature. Each pressure-temperature path is shown in Fig. 6 . The entropy of each path is (a) $7 \mathrm{~kJ} / \mathrm{K} / \mathrm{kg}$, (b) $8 \mathrm{~kJ} / \mathrm{K} / \mathrm{kg}$, (c) $9 \mathrm{~kJ} / \mathrm{K} / \mathrm{kg}$, and (d) $10 \mathrm{~kJ} / \mathrm{K} / \mathrm{kg}$. The elemental composition is C/H/O/Si $=1 / 2 / 10 / 5$ for all the cases.

The equilibrium compositions are determined by searching for the composition that gives the minimum Gibbs free energy at a given temperature and pressure. Then entropy is calculated using the determined composition. The composition along an isentropic path is determined as follows: First, we iteratively look for the pressure value whose entropy coincides with the entropy for a given isentropic curve at each temperature using our above-mentioned equilibrium calculation code. Then, we calculate the equilibrium composition for this pressure and temperature condition. When we repeat this calculation for different temperatures, we obtain the compositions along an isentropic path.

\subsection{Calculation results and comparison with LPV ex- periments}

The results of thermodynamic equilibrium calculations along each isentropic path are shown in Fig. 5. The amount of produced species normalized by the number of moles of total carbon atoms in the reaction system is shown as a function of quenching temperature. Calculated isentropic pressure-temperature paths along which the composition of products is determined are shown in Fig. 6. The calculation results for all the cases predict that $\mathrm{CO}$ and $\mathrm{CO}_{2}$ are the main carbon-bearing species and that the abundance of $\mathrm{CO}$ is larger than that of $\mathrm{CO}_{2}$ at $\sim 3000 \mathrm{~K}$, which is a general quenching temperature predicted for small laboratory-scale vapor plumes (Gerasimov et al., 1998). Thus, those results are consistent with the results of LPV experiments. It is noted that our calculation results indicate that $\mathrm{CO}$ and $\mathrm{CO}_{2}$ are produced even at low quenching temperatures $(<2000$ $\mathrm{K})$ as well as high quenching temperatures. This will be discussed in Section 4.2. In contrast, hydrocarbons $\left(\mathrm{CH}_{4}\right.$ and $\mathrm{C}_{2} \mathrm{H}_{2}$ ) are not produced in the calculations, while those species are produced in the LPV experiments. This is consistent with the idea mentioned in Section 2 that $\mathrm{CH}_{4}$ and $\mathrm{C}_{2} \mathrm{H}_{2}$ detected in the LPV experiments may be the products within vapor plumes but the secondary products by catalytic 


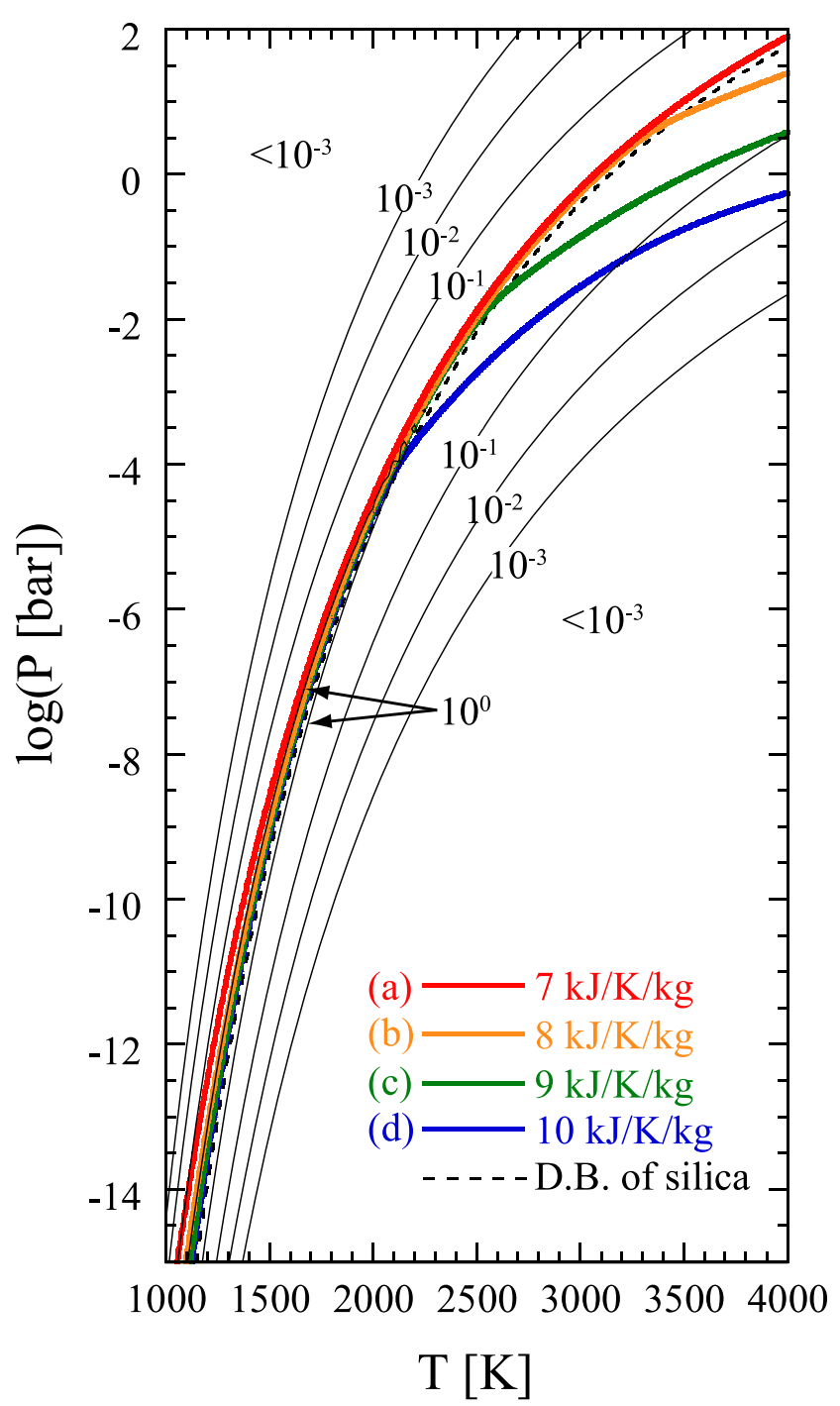

Fig. 6. Isentropic pressure-temperature paths along which the equilibrium composition of products are calculated (cf., Fig. 5). Entropy of each path is (a) $7 \mathrm{~kJ} / \mathrm{K} / \mathrm{kg}$, (b) $8 \mathrm{~kJ} / \mathrm{K} / \mathrm{kg}$, (c) $9 \mathrm{~kJ} / \mathrm{K} / \mathrm{kg}$, and (d) $10 \mathrm{~kJ} / \mathrm{K} / \mathrm{kg}$. The decomposition boundary (D.B.) of pure silica is also shown. Silica decomposes mainly into $\mathrm{SiO}, \mathrm{O}$, and $\mathrm{O}_{2}$ in the high-temperature side of the boundary, and silica does not decompose in the low-temperature side of the boundary. Calculated contour lines of the $\mathrm{CO}_{2} / \mathrm{CO}$ ratio are also shown by solid black lines.

reactions or from polyethylene melts. Thus, the results of LPV experiments for a nominal case can be explained thermodynamically.

Then, we will consider the effects of scale and laser intensity. In Fig. 7, the $\mathrm{CO}_{2} / \mathrm{CO}$ ratio is shown as a function of temperature for different entropy values. Laser intensity dependence on the $\mathrm{CO}_{2} / \mathrm{CO}$ ratio obtained by the LPV experiments is consistent with the model calculations. In the LPV experiments, the $\mathrm{CO}_{2} / \mathrm{CO}$ ratio decreases as laser intensity increases, which leads to increase in entropy gain (Fig. 4). The calculation results show that the $\mathrm{CO}_{2} / \mathrm{CO}$ ratio decreases as entropy gain increases at high temperatures, 2500-3000 K, where chemical reactions in LPV plumes might be quenched (Fig. 7). This is the same trend as experimental results.

In contrast, the observed plume scale dependence on the $\mathrm{CO}_{2} / \mathrm{CO}$ ratio cannot be reproduced by the model calcu- lation. Increase in vapor plume scale leads to decrease in quenching temperature because the cooling rate with adiabatic expansion for larger plumes is lower than that for smaller plumes. In the LPV experiments, the $\mathrm{CO}_{2} / \mathrm{CO}$ ratio slightly decreases as the scale of vapor plume increases (Fig. 3). However, the results of the thermodynamic calculations show that the $\mathrm{CO}_{2} / \mathrm{CO}$ ratio increases as quenching temperature decreases at high temperatures (Fig. 7). Furthermore, the $\mathrm{CO}_{2} / \mathrm{CO}$ ratios obtained in the LPV experiments are less than 0.09 (Figs. 3 and 4), which is smaller than the values obtained from the calculations by more than a factor of ten at probable quenching temperatures between 2500 and $3000 \mathrm{~K}$ (Fig. 7). Thus, other cooling processes in addition to adiabatic cooling may be needed to explain these trends of the $\mathrm{CO}_{2} / \mathrm{CO}$ ratio. Contours for the equilibrium $\mathrm{CO}_{2} / \mathrm{CO}$ ratio are shown in Fig. 6 along with the adiabatic $p-T$ paths. Note that the $\mathrm{CO}_{2} / \mathrm{CO}$ ratio is the highest along the decomposition boundary curve of $\mathrm{SiO}_{2}$ and that the ratio is lower under conditions further away from the boundary curve. The pace of change in the $\mathrm{CO}_{2} / \mathrm{CO}$ ratio as a function of temperature depends on the difference in slope between the adiabatic path and the $\mathrm{CO}_{2} / \mathrm{CO}$ contour curve. Figure 6 also shows that when a vapor cools along an adiabatic path, the $\mathrm{CO}_{2} / \mathrm{CO}$ ratio increases before the path reaches the decomposition boundary. After reaching the decomposition boundary, the curve bends and becomes practically parallel to the contour curves. This is the reason why $\mathrm{CO}_{2} / \mathrm{CO}$ ratio increases as temperature decreases at higher temperatures $(>\sim 1500 \mathrm{~K})$ as shown in Fig. 7. However, if the $p$ - $T$ paths deviate from the decomposition boundary of $\mathrm{SiO}_{2}$ at the end of cooling toward lower temperature conditions where the $\mathrm{CO}_{2} / \mathrm{CO}$ ratio decreases with decrease in temperature, decrease in the $\mathrm{CO}_{2} / \mathrm{CO}$ ratio will occur as observed in our experiments. Thus, mechanisms that cool vapor plumes more rapidly than adiabatic cooling for a given pressure decrease, such as radiative cooling and mixing with ambient atmosphere, would fill the gap between observed trends and an adiabatically cooling equilibrium model. Since vapor plume pressure at probable quenching temperatures $(2500$ to $3000 \mathrm{~K})$ is much higher $\left(10^{-2}\right.$ to 1 bar, Fig. 7) than the ambient pressure in the LPV experiments $\left(1 \times 10^{-3}\right.$ mbar $)$, mixing between expanding vapor plumes and the ambient air is probably not efficient. In contrast, since the scale of the plumes in the LPV experiments is small, radiation may contribute to cooling efficiently. Thus, high radiation efficiency due to the smallness of plumes may account for the difference in the $\mathrm{CO}_{2} / \mathrm{CO}$ ratio between the results of the LPV experiments and the predictions of theoretical calculation that does not consider radiation.

The calculation results also indicate that $\mathrm{SiO}, \mathrm{O}$, and $\mathrm{O}_{2}$ are produced. However, those species are not detected in the actual LPV experiments. This experimental result might suggest that after reactions related to $\mathrm{CO}$ and $\mathrm{CO}_{2}$ have been quenched, reactions related to $\mathrm{SiO}, \mathrm{O}$, and $\mathrm{O}_{2}$ are still active (i.e., not single quenching) and that those species may be lost by $\mathrm{SiO}_{2}$ formation and condensation or some other mechanisms. This will be discussed in Section 4.1. 

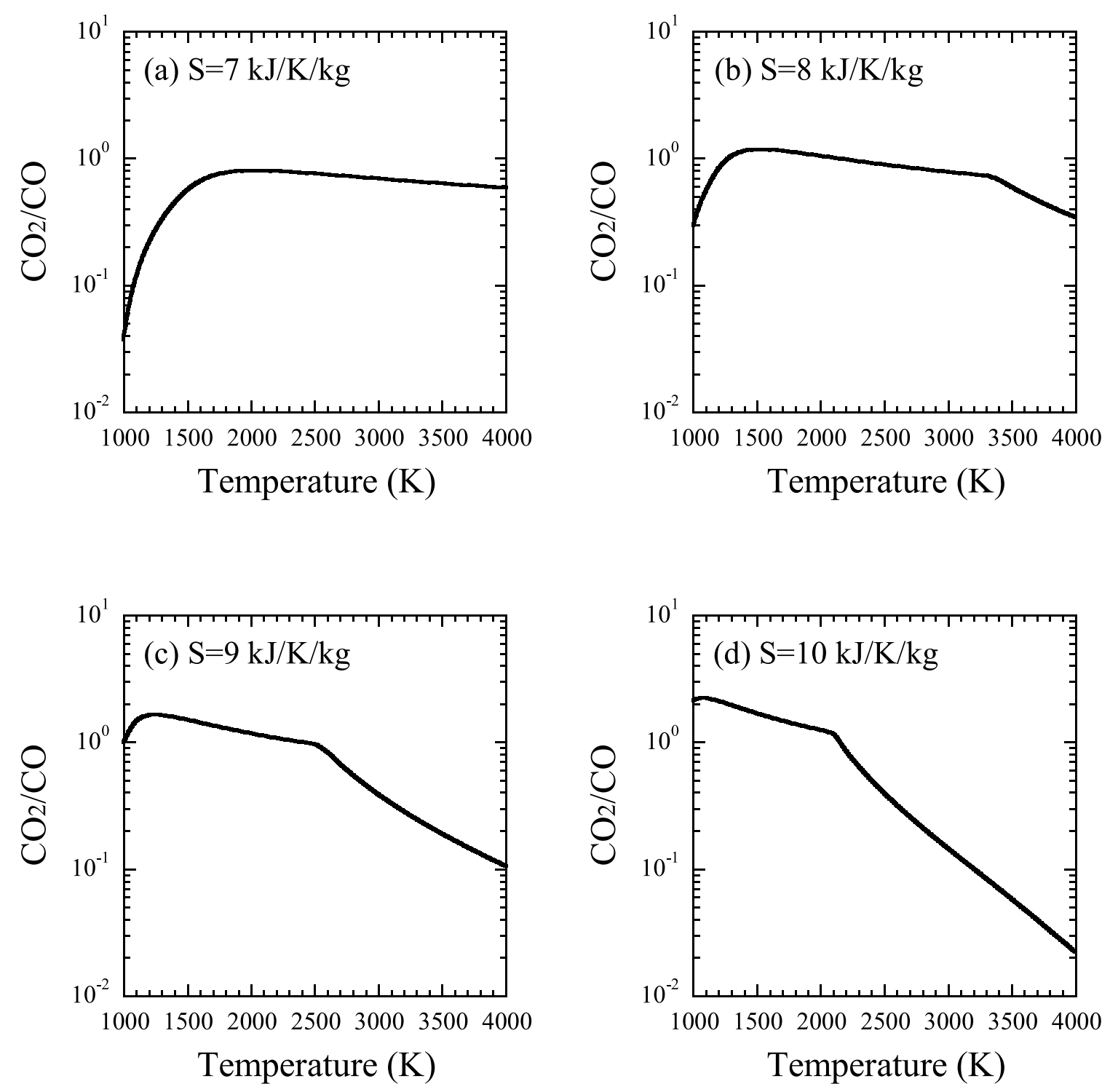

Fig. 7. Calculated $\mathrm{CO}_{2} / \mathrm{CO}$ ratios along isentropic pressure-temperature paths as a function of quenching temperature. The corresponding pressure-temperature paths are shown in Fig. 6. The entropy of the paths are (a) $7 \mathrm{~kJ} / \mathrm{K} / \mathrm{kg}$, (b) $8 \mathrm{~kJ} / \mathrm{K} / \mathrm{kg}$, (c) $9 \mathrm{~kJ} / \mathrm{K} / \mathrm{kg}$, and (d) $10 \mathrm{~kJ} / \mathrm{K} / \mathrm{kg}$, respectively.

\section{Discussion}

\subsection{The fate of silica that released oxygen}

Since oxygen released from silica is used in reactions with carbon, silica should be reduced. The thermodynamic equilibrium calculations indicate that $\mathrm{SiO}_{2}$ decomposes into gaseous $\mathrm{SiO}, \mathrm{O}$, and $\mathrm{O}_{2}$ at high temperatures. Thus, gaseous $\mathrm{SiO}$ remains after oxygen is used in reactions with carbon compounds. However, $\mathrm{SiO}, \mathrm{O}$, and $\mathrm{O}_{2}$ are not detected in the LPV experiments. This suggests that reactions related to these species are still active after reactions related to carbon-bearing species quench, and $\mathrm{SiO}$ might combine with $\mathrm{O}$ and $\mathrm{O}_{2}$ at low temperatures (i.e., not single quenching). However, since a part of oxygen combines with carbon, $\mathrm{SiO}$ is stoichiometrically more abundant than $\mathrm{O}$ and $\mathrm{O}_{2}$. Thus, it cannot be accounted for by these reactions alone. Other possibilities are that both solid $\mathrm{SiO}_{2}$ and metallic $\mathrm{Si}$ are generated through disproportionation reactions of SiO (e.g., Mamiya et al., 2001; Han et al., 2003) and that solid $\mathrm{SiO}$ is produced. Though solid $\mathrm{SiO}$ is known to be unstable at any temperature and atmospheric pressure (Brewer and Green, 1957), vapor condensates consist of metastable substances under some conditions (e.g., Nuth and Donn, 1982; Rietmeijer et al., 1999). Generation of reduced-state silicon, such as $\mathrm{Si}^{0}$, in LPV experiments is also reported although the elemental composition of the reaction system is considerably different from ours; more metallic elements, such as $\mathrm{Ca}, \mathrm{Mg}$ and $\mathrm{Al}$, are included (Dikov et al., 1996; Gerasimov et al., 1996). Those experiments suggest that disproportionation reactions generating reduced Si may occur within vapor plumes. What substances are generated could be revealed through the investigation of condensates generated by the LPV experiments. However, the recovered amount of the condensed matter is too little to analyze accurately. Improvement in a condensate-recovery method is needed for resolving this issue.

4.2 The effect of vapor plume scale and gained entropy

The scale of vapor plumes in LPV experiments is $\sim 10^{-3}$ $10^{-4} \mathrm{~m}$ while that of asteroidal and cometary impacts on surfaces of planets is typically up to $10^{6} \mathrm{~m}$. Quenching temperature of chemical reactions within vapor plumes de- 
creases as the scale of vapor plumes increases. For example, quenching temperature is estimated to be $\sim 3000$ $\mathrm{K}$ for laboratory-scale plumes and $\sim 2000 \mathrm{~K}$ for plumes produced by impacts of projectiles several kilometer in diameter (Gerasimov, 1998). In previous theoretical studies of impact-induced vapor plumes, silicate components are removed from calculations because those components are thought to be condensed completely because of low quenching temperature.

However, the results of thermodynamic calculations along isentropic pressure-temperature paths indicate that at least silica should not be removed from calculations. The results of calculations indicate that silica does not condense completely and that large amount of $\mathrm{CO}$ and $\mathrm{CO}_{2}$ are produced even at low temperatures $(<2000 \mathrm{~K})$ where the reactions quench in planetary-scale vapor plumes (Fig. 5). Why did not silica condense completely even at low temperatures? In Fig. 6, though each path goes through different point at high temperatures, all paths converge to almost the same curve at low temperatures. This curve is located approximately along the decomposition boundary of pure silica. Thus, adiabatic pressure-temperature paths are "trapped" by the silica decomposition boundary. Pressure decreases steeply as temperature decreases, and pressure and temperature conditions could not reach where silica completely condenses. Thus, silica does not condense completely, and oxidation of carbon by silica-derived oxygen occurs as long as plumes cool adiabatically. In general, planetary-scale vapor plumes that are larger than atmospheric scale height of planets cool adiabatically. Thus, oxidation of carbon by silica is likely to occur even in planetary-scale vapor plumes.

Entropy of impact-induced vapor plumes increases with impact velocity. As mentioned in Section 2.1, entropy gained by our LPV experiments are estimated to be $\sim 10$ $\mathrm{kJ} / \mathrm{K} / \mathrm{kg}$, which corresponds to impacts with velocity of several tens of $\mathrm{km} / \mathrm{s}$ to hundred $\mathrm{km} / \mathrm{s}$ (Kadono et al., 2002; Sugita et al., 2003), which is higher than the mean impact velocity of asteroids to the Earth (Chyba, 1991). However, the results of thermodynamic equilibrium calculations along adiabatic pressure-temperature paths suggest that difference in entropy gained by impact does not so much affect the vapor composition at low quenching temperatures where the chemical reactions within planetary-scale vapor plumes are expected to quench $(<2000 \mathrm{~K})$. Adiabatic pressure-temperature paths converge to almost the same curve at low temperatures (Fig. 6), and the vapor composition becomes almost the same at low temperatures (Fig. 5). Thus, oxidation of carbon compounds by silicaderived oxygen may occur regardless of impact velocity as long as silica vaporizes.

Here it is noted that coexistence between vapor-phase $\mathrm{SiO}-\mathrm{O}_{2}$ and condensed-phase $\mathrm{SiO}_{2}$ will continue down to extremely low-temperatures and pressures thermodynamically (e.g., Zel'dovich and Raiser, 1967). Thus, the $\mathrm{SiO}_{2}-$ derived $\mathrm{O}_{2}$ continues to react with carbon-bearing species. However, such adiabatic expansion process would be interfered by other processes, such as radiative cooling or mixing with ambient atmosphere and cease in thermodynamic equilibration due to the low molecular density. Neverthe- less, the tendency that oxygen derived from $\mathrm{SiO}_{2}$ play an important role in vaporized meteoritic materials will not be affected significantly by these processes.

\section{Summary}

We investigate experimentally and theoretically whether carbon is oxidized by oxygen derived from $\mathrm{SiO}_{2}$ within impact-induced carbon-poor vapor plumes.

First, we conducted laser pulse vaporization (LPV) experiments on polyethylene-silica mixture, which simulate hypervelocity impacts of carbonaceous chondritic impactors, to investigate whether silica-derived oxygen reacts with carbon compounds in laser-induced vapor plumes. Though polyethylene contains no oxygen, the produced gas from polyethylene-silica mixture contains significant amounts of $\mathrm{CO}$ and $\mathrm{CO}_{2}$. In addition, the production ratio of $\mathrm{CO}$ and $\mathrm{CO}_{2}$ monotonically increases as silica mixing ratio in targets increases. When the laser irradiation conditions (i.e., laser beam diameter and laser intensity) are changed, the trends do not change. These results unambiguously show that silica-derived oxygen reacts with carbon compounds within vapor plumes.

Second, we carried out the thermodynamic equilibrium calculations to examine whether the results of the LPV experiments could be explained thermodynamically. The calculation results indicate that both $\mathrm{CO}$ and $\mathrm{CO}_{2}$ are produced, and the amount of $\mathrm{CO}$ is larger than $\mathrm{CO}_{2}$ at the estimated quenching temperature of LPV vapor plumes. Those results are consistent with the results of LPV experiments. The dependence of vapor composition $\left(\mathrm{CO}_{2} / \mathrm{CO}\right.$ ratio $)$ on entropy gained by laser irradiation is explained by adiabatic cooling of vapor plumes. The dependence of vapor composition on plume scale seems not to be explained by adiabatic cooling only. Thus, additional cooling processes, such as radiative cooling may be important at laboratory-scale vapor plumes.

The calculation results also indicate that oxidation of carbon by silica-derived oxygen occurs even at low quenching temperatures $(<2000 \mathrm{~K})$ as long as plumes cool adiabatically. Thus, though quenching temperatures in those planetary-scale vapor plumes are lower than those in laboratory-scale vapor plumes, oxidation of carbon by silica-derived oxygen might occur. In addition, the calculation results indicate that isentropic pressure-temperature paths are converged to decomposition boundary of silica at low temperatures, and the composition of products are almost the same at those temperatures.

We conclude that carbon compounds in impactors are likely to be oxidized by oxygen derived from $\mathrm{SiO}_{2}$, the main component of silicate, within planetary-scale vapor plumes produced by hypervelocity impacts regardless of impact velocity as long as silica is vaporized.

Acknowledgments. The authors thank K. Kuramoto for insightful discussions during the early phase of this study. H. Yoshida for technical assistance in target preparation. We appreciate the constructive comments from Dr. M. V. Gerasimov and the anonymous reviewer. This research was partly supported by the Grant in Aide from Japan Society for the Promotion of Science. 


\section{References}

Biernacki, J. J. and G. P. Wotzak, Stoichiometry of the $\mathrm{C}+\mathrm{SiO}_{2}$ reaction, J. Am. Ceram. Soc., 12, 122-129, 1989a.

Biernacki, J. J. and G. P. Wotzak, Thermogravimetric study of the $\mathrm{C}+\mathrm{SiO}_{2}$ reaction, J. Thermal Anal., 35, 1651-1667, 1989b.

Brewer, L. and F. T. Green, Differential thermal analysis of the $\mathrm{Si}_{-} \mathrm{SiO}_{2}$ system, J. Phys. Chem. Solids, 2, 286-288, 1957.

Chan, W. T. and R. E. Russo, Study of laser-material interactions using inductively coupled plasma-atomic emission spectrometry, Spectrochim. Acta, 46B, 1471-1486, 1991.

Chase, M. W., C. A. Davies, J. R. Downey, D. J. Frurip, R. A. McDonald, and A. N. Syverud, JANAF thermochemical tables, 3rd ed., J. Phys. Chem. Ref. Data, 14, Suppl. 1, 1-1856, 1985.

Chyba, C., Terrestrial mantle siderophiles and the Lunar impact record, Icarus, 92, 217-233, 1991.

Chyba, C. and C. Sagan, Endogenous production, exogenous delivery and impact-shock synthesis of organic molecules: an inventory for the origins of life, Nature, 355, 125-132, 1992.

Dikov, Yu. P., M. V. Gerasimov, O. I. Yakovlev, and F. Wlotzka, Hightemperature vaporization of $\mathrm{Mg}$-Ca-carbonate-sulfate-quartz-alumina targets, Lunar Planet. Sci. XXVII, Abstract, 311-312, 1996.

Fegley, B., Jr., R. G. Prinn, H. Hartman, and G. H. Watkins, Chemical effects of large impacts on the earth's primitive atmosphere, Nature, 319, 305-308, 1986.

Gerasimov, M. V., On the release of oxygen from the intensively shocked meteorites and terrestrial rocks, Lunar Planet. Sci. XVIII, Abstract, 320 $321,1987$.

Gerasimov, M. V., Toxins produced by meteorite impacts and their possible role in a biotic mass extinction, in Catastrophic Events and Mass Extinctions: Impacts and Beyond, edited by Koeberl, C. and MacLeod, K. G., Boulder, Colorado, Geological Society of America Special Papers, 356, 705-716, 2002.

Gerasimov, M. V., B. L. Satovsky, and L. M. Mukhin, Massspectrometrical analyses of gases originated during impulsive evaporation of meteorites and terrestrial rocks, Lunar Planet. Sci. XVIII, Abstract, 322-323, 1987.

Gerasimov, M. V., Yu. P. Dikov, O. I. Yakovlev, and F. Wlotzka, Reduction of carbon during high temperature vaporization in the calciumcarbonate-silicate system, Lunar Planet. Sci. XXVII, Abstract, 401-402, 1996.

Gerasimov, M. V., B. A. Ivanov, O. I. Yakovlev, and Yu. P. Dikov, Physics and chemistry of impacts, Earth Moon Planets, 80, 209-259, 1998.

Hallstedt, B., Thermodynamic assessment of the silicon-oxygen system, Calphad, 16, 53-61, 1992.

Han, M., J. F. Zhou, F. Q. Song, C. R. Yin, M. D. Liu, J. G. Wan, and G. H. Wang, Silicon-riched-oxide cluster assembled nanostructures formed by low energy cluster beam deposition, Europ. Phys. J. D, 24, 269-272, 2003.

Hashimoto, G. L., Y. Abe, and S. Sugita, The chemical composition of the early terrestrial atmosphere: Formation of a reducing atmosphere from CI-like material, J. Geophys. Res., 112, E05010, doi:10.1029/2006JE002844, 2007.

Ishimaru, R., H. Senshu, S. Sugita, and T. Matsui, Numerical simulation of chemical reactions within a vapor plume induced by cometary impact,
Lunar Planet. Sci. XXXVI, Abstract \# 1601, 2005.

Kadono, T., S. Sugita, N. K. Mitani, M. Fuyuki, S. Ohno, Y. Sekine, and T. Matsui, Vapor clouds generated by laser ablation and hypervelocity impact, Geophys. Res. Lett., 29(20), 1979, doi:10.1029/2002GL015694, 2002.

Kasting, J. F., Bolide impacts and the oxidation state of carbon in the earth's early atmosphere, Orig. Life Evol. Biosph., 20, 199-231, 1990.

Klinger, N., E. L. Strauss, and K. L. Komarek, Reactions Between Silica and Graphite, J. Am. Ceram. Soc., 49, 369-375, 1966.

Kress, M. and C. P. McKay, Formation of methane in comet impacts: implications for Earth, Mars, and Titan, Icarus, 168, 475-483, 2004.

Mamiya, M., H. Takei, M. Kikuchi, and C. Uyeda, Preparation of fine silicon particles from amorphous silicon monoxide by the disproportionation reaction, J. Crystal Growth, 229, 457-461, 2001.

Managadze, G. G., W. B. Brinckerhoff, and A. E. Chumikov, Molecular synthesis in hypervelocity impact plasmas on the primitive Earth and in interstellar clouds, Geophys. Res. Lett., 30(5), 1247, doi:10.1029/2002GL016422, 2003.

Mao, X., W. T. Chan, M. Caetano, M. A. Shannon, and R. E. Russo, Preferential vaporization and plasma shielding during nano-second laser ablation, Appl. Surf. Sci., 96-98, 126-130, 1996.

McKay, P. C., W. R. Borucki, D. R. Kojiro, and F. Church, Shock production of organics during cometary impact, Lunar Planet. Sci. XX, Abstract, 671-672, 1989.

Mukhin, L. M., M. V. Gerasimov, and E. N. Safnova, Origin of precursors of organic molecules and mafic terrestrial rocks, Nature, 340, 46-48, 1989.

Nuth, J. A. and B. Donn, Experimental studies of the vapor phase nucleation of refractory compounds. I. The condensation of SiO, J. Chem. Phys., 77, 2639-2646, 1982.

Ohno, S., S. Sugita, T. Kadono, S. Hasegawa, and G. Igarashi, Sulfur chemistry in laser-simulated impact vapor clouds: implications for the K/T impact event, Earth Planet. Sci. Lett., 218, 347-361, 2004.

Prigogine, I. and R. Defay, Chemical Thermodynamics, 543 pp., Longmans, London, 1954.

Rietmeijer, F. J. M., J. A. Nuth, and J. M. Karner, Metastable eutectic condensation in a $\mathrm{Mg}-\mathrm{Fe}-\mathrm{SiO}-\mathrm{H}_{2}-\mathrm{O}_{2}$ vapor: Analogs to circumstellar dust, Astrophys. J., 572, 395-404, 1999.

Russo, R. E., Laser ablation, Appl. Spectrosc., 49, 14A-28A, 1995.

Sugita, S., T. Kadono, S. Ohno, K. Hamano, and T. Matsui, Does laser ablation vapor simulate impact vapor?, Lunar Planet. Sci. XXXIV, Abstract \#1573, 2003.

Sugita, S., K. Kurosawa, T. Kadono, and T. Sano, An high-precistion semianalytical on-Hugoniot EOS for geologic materials, Lunar Planet. Sci. XLIII, Abstract \#1659, 2012.

Wasson, J. T. and G. W. Kallemeyn, Compositions of chondrites, Phil. Trans. R. Soc. Lond., A 325, 535-544, 1988.

Zel'dovich, Ya. B. and Yu. P. Raiser, Physics of Shock Waves and Hightemperature Hydrodynamic Phenomena, 916 pp., Academic Press, New York, 1967.

K. Ishibashi (e-mail: ko.ishibashi@perc.it-chiba.ac.jp), S. Ohno, S. Sugita, T. Kadono, and T. Matsui 